\title{
超臨界流体抽出法における環境污染有機化合物の抽出特性の解析
}

\author{
山本あずさ ${ }^{\circledR 1}$, 永井 一聡 ${ }^{2}$, 坂本 哲夫 ${ }^{2}$, 尾張 真則 ${ }^{2,3}$, 二瓶 好正 ${ }^{1}$
}

\section{Extraction behavior of environmental organic pollutants in supercritical fluid extraction}

\author{
Azusa Yамамото ${ }^{1}$, Kazuaki Nagai ${ }^{2}$, Tetsuo SAKAмото ${ }^{2}$, \\ Masanori OWARI $^{2,3}$ and Yoshimasa NIHEI ${ }^{1}$
}

\footnotetext{
${ }^{1}$ Department of Pure and Applied Chemistry, Tokyo University of Science, 2641 Yamazaki, Noda-shi, Chiba $278-8510$

${ }^{2}$ Environmental Science Center, The University of Tokyo, 7-3-1, Hongo, Bunkyo-ku, Tokyo 113 - 0033

${ }^{3}$ Institute of Industrial Science, The University of Tokyo, 4-6-1, Komaba, Meguro-ku, Tokyo 153 - 8505
}

(Received 27 January 2004, Accepted 18 April 2004)

\begin{abstract}
Aiming at the development of a rapid-analysis technique for environmental organic pollutants on suspended particulate matter (SPM) in air, a supercritical fluid extraction (SFE) technique was studied. The extraction efficiencies of typical organic pollutants spiked in alumina particles were first examined at various combinations of the extraction temperatures and pressures. The recovery of polyaromatic hydrocarbons (PAHs) showed strong dependence on both the extraction temperature and the pressure. This result was disscussed in terms of the enhanced solubilities and desorption/diffusion rates at a higher temperature and pressure. As for $n$-octadecane and tetrachlorobenzene, they showed little dependence on the fluid conditions. This implied that solubility has little effect on the recovery in case of these compounds with relatively high vapor pressures. The extraction behavior was also investigated using real SPM. Phthalates and Phenanthrene showed the maximum recovery at the highest temperature and pressure among three-step extraction, whereas $n$-alkanes and polysiloxanes were effectively extracted in the medium temperature and pressure step. The apparent difference in the extraction behavior implies the possibility of the selective extraction of the aimed analytes from real environmental samples.
\end{abstract}

Keywords : SFE; supercritical fluid; extraction; environmental analysis; PAHs.

\section{1 緒言}

大気中に浮遊している粒子状物質 (suspended particulate matters, SPM）の表面に付着している有機化合物は, SPM の生成時や大気中に浮遊している間の化学反応によ って生成される。現在，SPM上の有機化合物は様々な観 点から発生起源や人体への健康影響が調査されている。な

\footnotetext{
${ }^{1}$ 東京理科大学理工学研究科：278-8510 千葉県野田市山崎 2641

2 東京大学環境安全研究センター: 113-0033 東京都文京区本郷 7-3-1

${ }^{3}$ 東京大学生産技術研究所：153-8505 東京都目黒区駒場 4-6-1
}

かでも，ディーゼル排ガスや燒却施設といった燃焼起源の SPM 上には, 多環芳香族炭化水素 (polycyclic aromatic hydrocarbons, PAHs) 及びニトロ PAHs といった発がん 性を有する有機化合物が付着しており，潜在的影響の評価 が多く行われている(1)2).

SPM に付着した有機化合物の分析は，サンプリング • 有機溶媒抽出・クリーンアップ（きょう雑物の除去）・濃 縮・ガスクロマトグラフィー/質量分析法（GC/MS）測定 から成る.このうち, 抽出・クリーンアップ・濃縮といっ た前処理は極めて手間が掛かるほか，時間やコストの面で も多くの問題を抱えている。これらの問題は抽出に時間が 
かかることや分析目的以外の有機化合物も一括に抽出する ことが原因であると考えられる.

現在, 多くの試料が迅速に抽出できる新たな抽出法とし て超臨界流体抽出法 (supercritical fluid extraction, SFE) が注目されており ${ }^{3) 4)}$, 食品の成分や香料の抽出, 更には 一部の環境分析にも利用されている ${ }^{5)}$. 多くの場合, 安価 で安全であるとの理由から二酸化炭素が流体として用い られる。超臨界流体は気体と液体の中間的な物理特性を有 し, 気体に近い拡散と液体なみの密度（=溶解力）を持つ ため, 高速な抽出が可能である. また, 流体の温度と圧力 に依存して溶解度が変化することから, 溶媒特性を制御す ることも可能である ${ }^{6)}$. しかしながら, SFEにおける抽出 率は流体条件のほかに有機化合物や吸着媒体の化学組成に も強く依存することが知られている7). したがって, SFE の迅速性を生かした環境試料の分析を実施するためには 種々の抽出条件における抽出率を把握することが前提とな る.

そこで本研究では, 最初にモデル吸着試料を使用して, 種々の流体条件における抽出率の変化を追うことで, 基本 的な抽出特性を検討する. 次いで，その知見を基に実際の SPM 試料を用い, 流体条件を 3 段階に変化させた多段階 抽出を行い, SPM に吸着した $n$-アルカン類, ポリシロキ サン類, フタル酸エステル類, $\mathrm{PAH}$ 類の抽出状態を調査 する。これらの実験から, SFEにおいて抽出効率に影響を 与える因子を検討し, 実試料における $\mathrm{SFE}$ の最適化と有 用性を明らかにすることを目的とした。

\section{2 実験}

\section{$2 \cdot 1$ モデル吸着試料の調製}

$\mathrm{PAH}$ 類（アントラセン，9,10-ジクロロアントラセン， ピレン，クリセン）及び 1,2,4,5-テトラクロロベンゼンを

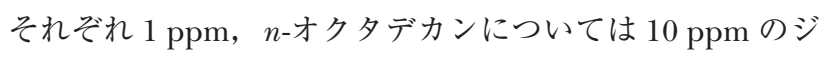
クロロメタン溶液を調製した. 次いでガラスビーカー内の 活性アルミナ（中性，粒子径 $0.063 \sim 0.200 \mathrm{~mm}$, Merck KGaA，Darmstadt, Germany) $1 \mathrm{~g}$ 当たり溶液を $1 \mathrm{ml}$ 添 加した後, 溶媒を室温にて蒸発させた。モデル吸着試料を 取り除いた後のビーカー壁面にトルエンを加え壁面に吸着 したモデル物質を回収し，GC/MSにより定量した。添加 した量とビーカーに残った量の差をモデル試料への吸着量 とした。この結果, ビーカー壁面における残存量は無視で き，モデル粒子への吸着濃度は $\mathrm{PAH}$ 類が $1 \mathrm{ppm}, n$-オク タデカンは $10 \mathrm{ppm}$ であった.

\section{$2 \cdot 2$ SPM 捕集}

SPM 試料として横浜市内の国道 1 号線沿道において, ローボリウム・エアサンプラー（L-30 型，柴田科学製） を使用し，ガラス繊維沪紙に吸引流量 30 1/min にて 1 日
8 時間ずつ 3 日間，計 24 時間捕集を行った。捕集した $\mathrm{SPM}$ 粒子の重量は湿度 $30 \%$ の乾燥機で乾燥後, ひょう量 したところ $10.2 \mathrm{mg}$ であった. SFE には沪紙の半分を使用 した。

\section{$2 \cdot 3$ SFE 装置及び抽出方法}

本研究で設計・製作した SFE 装置の構成を Fig. 1 に示 す。ボンベから $\mathrm{CO}_{2}$ （純度 $99.5 \%$ 以上，鈴木商館製）を サイフォンにて液取りした後, 安定液化のために $-10^{\circ} \mathrm{C}$ の冷却槽に浸した銅チューブ（外径 $1 / 8$ インチ，長さ $2 \mathrm{~m}$ ）を通した。液体 $\mathrm{CO}_{2}$ は高圧送液ポンプ（CCPD，東 ソー製) で加圧した。ポンプは定流量モードで運転した。 加圧された液体 $\mathrm{CO}_{2}$ は, GC オーブン (GC-8A, 島津製) 内で加熱され，超臨界状態に達する。オーブン温度は $40 \sim 399^{\circ} \mathrm{C}$ の間で設定することができる. 試料は内容積 8 $\mathrm{ml}$ の $1 / 2$ インチの SUS 316 管材料で製作した抽出セル中 に導入した。 セルの両端は石英ガラスウールを詰め, 試料 粒子の流出を防いだ。抽出された有機物は $\mathrm{CO}_{2}$ とともに, 内径 $30 \mu \mathrm{m}$, 長さ $65 \mathrm{~cm}$ の溶融シリカキャピラリーカラ ム（ジーエルサイエンス製）を通し，トルエンにバブリン グさせて減圧, 回収した。

\section{$2 \cdot 4$ モデル試料を用いた回収率の測定}

$2 \cdot 1$ で作製したモデル試料を用い，抽出温度 $50^{\circ} \mathrm{C}$ 及び $100^{\circ} \mathrm{C}$ において, それぞれ抽出圧力 $10,20,30 \mathrm{MPa}$ とし た場合の各吸着物質の回収率（＝回収量/吸着量 $\times 100 \%)$ を求めた.モデル試料は 1 回の抽出に $0.5 \mathrm{~g}$ を使用し, 回 収溶媒はトルエンを $5 \mathrm{ml}$ 用いた。抽出時間はスタティッ ク抽出を 30 分, 次いでダイナミック抽出を 30 分行った. ここで, スタティック抽出とは, 抽出セル出口バルブ （Fig. 1 中 Valve3）を閉じ, 超臨界流体を抽出セル内に滞 留させることを意味する。一方, ダイナミック抽出は出口 バルブを開け，流体を連続的に流しながら抽出物を回収す る方法である。

抽出物を含んだ回収液は, 乾燥窒素を吹き付けながら室 温で $1 \mathrm{ml}$ に濃縮した後，GC/MSによって各吸着物質の 回収率を求めた。

\subsection{SPM 実試料の抽出}

SPM を捕集したガラス繊維沪紙を抽出セル内に入れ，3 段階に流体条件を変えた SFE 抽出を行った。各ステップ における超臨界 $\mathrm{CO}_{2}$ の圧力, 温度及び密度を Table 1 に 示す. 密度計算は Lee-Kesler の方程式に基づいて行った ${ }^{8)}$. 各抽出はスタティック抽出を 10 分間, ダイナミック抽出 を 60 分間で構成した。 各ステップでの抽出物はそれぞれ $5 \mathrm{ml}$ のジクロロメタンに回収した。回収溶液は乾燥窒素 ガスを用いて $1 \mathrm{ml}$ に濃縮した。 


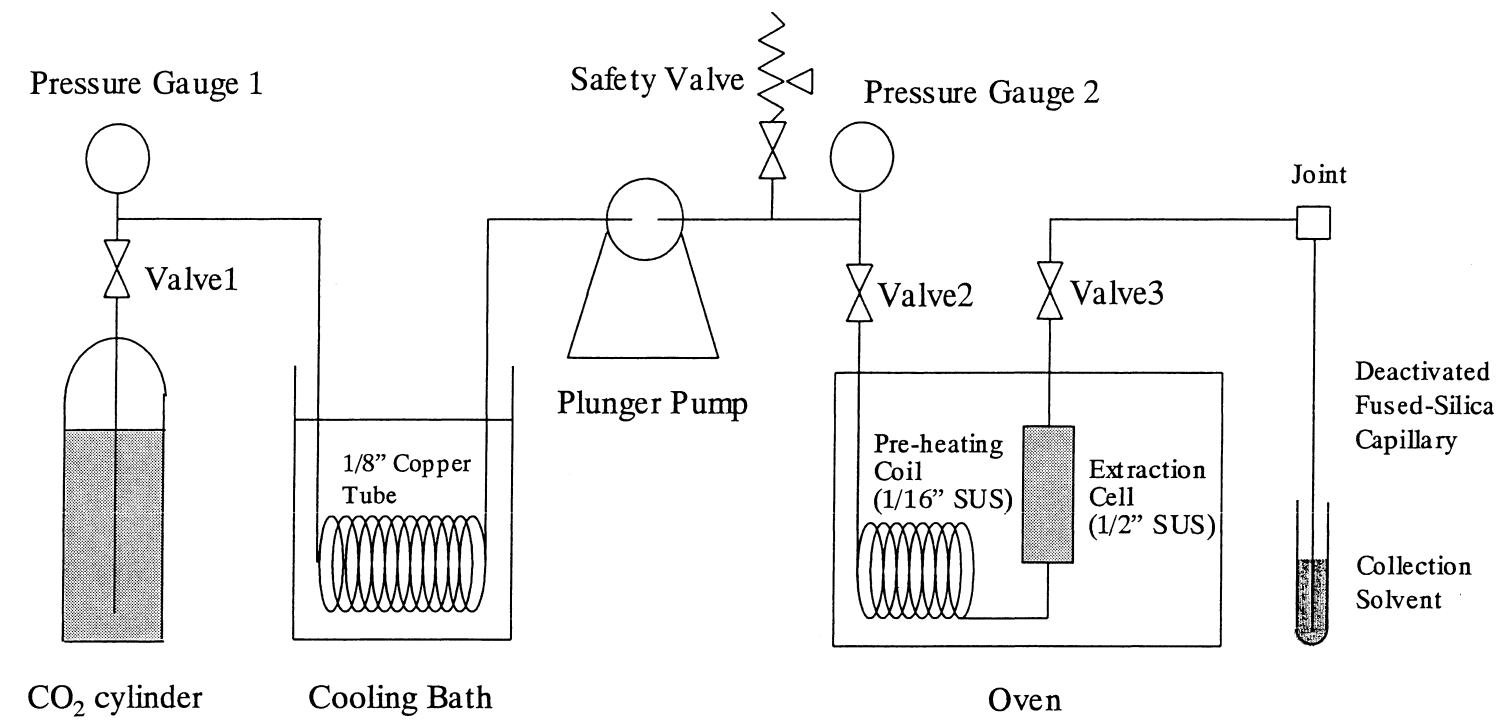

Fig. 1 Schematic diagram of the SFE apparatus

The medium in the cooling bath is water/ethyleneglycol mixture. The safety valve opens above $40 \mathrm{MPa}$. When Valve 3 is closed the fluid is stationary (static extraction), the fluid does not flow and static extraction is occurred, whereas it is opened dynamic extraction mode is performed.

Table 1 Supercritical $\mathrm{CO}_{2}$ conditions in the threestep extraction

\begin{tabular}{cccc}
\hline & Temperature $/{ }^{\circ} \mathrm{C}$ & Pressure $/ \mathrm{MPa}$ & Density $/ \mathrm{g} \mathrm{ml}^{-1}$ \\
\hline Step1 & 60 & 10 & 0.29 \\
Step2 & 80 & 20 & 0.58 \\
Step3 & 120 & 30 & 0.58 \\
\hline
\end{tabular}

\section{$2 \cdot 6 \mathrm{GC} / \mathrm{MS}$ 装置条件}

モデル試料の回収液は四重極型質量分析計を備えた GC/MS（HP6890/HP5973A，横河アナリティカルシステ ムズ製）を用いて抽出物を定量した。キャピラリーカラム は DB-5（膜厚 $0.25 \mu \mathrm{m}$, 内径 $0.249 \mathrm{~mm}$, 長さ $30 \mathrm{~m}$ ）を 用い，温度プログラムは， $50 \sim 300^{\circ} \mathrm{C}$ まで $10^{\circ} \mathrm{C} / \mathrm{min}$ で昇 温後 5 分間保持した.

SPM 実試料については回収量が微量であると予想され たため, 高分解能 GC/MS 装置（VG Autospec Ultima，ジ ヤスコインターナショナル製）を用いて定性分析した。キ ヤピラリーカラムは DB-5 を使用し， $60^{\circ} \mathrm{C}$ で 1 分保持した 後, $20^{\circ} \mathrm{C} / \mathrm{min}$ で $180^{\circ} \mathrm{C}$ まで昇温させ, その後 $10^{\circ} \mathrm{C} / \mathrm{min}$ で $280^{\circ} \mathrm{C}$ まで昇温， 10 分間保持した. MS は透過率を優 先して質量分解能 $m / \Delta m=1000$ とした。 $m / z$ 軸は perfluorokerosene を用いて校正した。

\section{3 結果と考察}

\section{$3 \cdot 1$ モデル試料における回収率の圧力・温度依存性}

Fig. 2 にアルミナ粒子に吸着させたモデル物質の $50^{\circ} \mathrm{C}$
及び $100{ }^{\circ} \mathrm{C} に$ に打る回収率を示す。この結果，回収率の 抽出圧力への依存性は 2 つの傾向に大別された。抽出温 度 $50^{\circ} \mathrm{C}, 100^{\circ} \mathrm{C}$ 双方に扔いて, $n$-オクタデカンとテトラ クロロベンゼンの回収率は圧力に対して大きな依存性を示 さなかった。また，テトラクロロベンゼンについては $50^{\circ} \mathrm{C}$ から $100^{\circ} \mathrm{C}$ に上昇させると回収率は圧力に関係なく 100\% 前後に達した。一方, PAH 類（アントラセン，ジ クロロアントラセン，ピレン，クリセン）は，圧力の上昇 に伴って回収率が大幅に増加する傾向が見られた．50 $\mathrm{C}$ と $100{ }^{\circ} \mathrm{C}$ で比較すると, 各物質とも $20 \mathrm{MPa}$ 及び $30 \mathrm{MPa}$ ではそれぞれ $50^{\circ} \mathrm{C}$ の場合と比べ $100^{\circ} \mathrm{C}$ のほうが高い回収 率となった。

SFE において回収率に影響を与える因子は複数あるが, 主として考えられるのは超臨界 $\mathrm{CO}_{2}$ に対する吸着物質の 溶解度と脱離・拡散速度である. 各々の効果を独立に議論 することは困難であるため，ここでは各因子の変化傾向を 考察する。

$$
y_{2}=\frac{p_{2}^{\text {sat }}}{p} \frac{1}{\varphi_{2}^{\mathrm{G}}} \exp \left[\frac{\nu_{2}^{\mathrm{S}}\left(p-p_{2}^{\mathrm{sat}}\right)}{R T}\right]
$$

超臨界流体に対する溶質（有機化合物）の溶解度 $y_{2}$ は 式 (1) で表される ${ }^{8)}$ 。ここで, $p_{2}^{\text {sat }}$ は溶質の飽和蒸気圧, $p$ は超臨界流体の圧力, $\varphi_{2}^{\mathrm{G}}$ は溶質の気相フガシチー係数, $\nu_{2}^{\mathrm{S}}$ は溶質の固体モル体積, $R$ は気体定数, $T$ は超臨界流 体の絶対温度である。式 (1) から溶解度は超臨界流体の 圧力と溶質の蒸気圧に大きく依存することが分かる。一般 

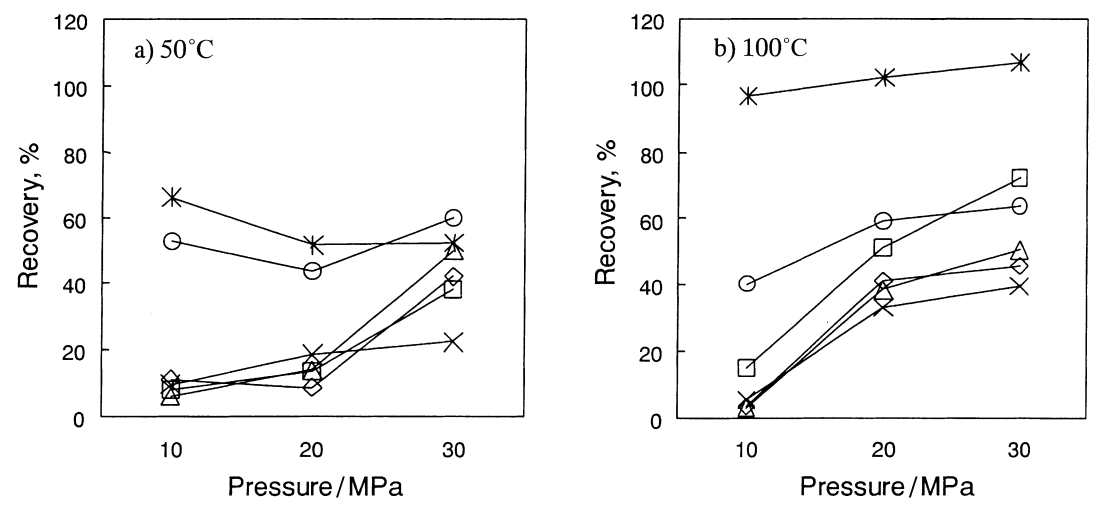

Fig. 2 Recoveries of model compounds adsorbed on alumina particles at extraction temperatures of a) $50^{\circ} \mathrm{C}$ and b) $100^{\circ} \mathrm{C}$, respectively

Symbols: anthracene $(\diamond), 9,10$-dichloroanthracene $(\square)$, pyrene $(\triangle)$, chrysene $(\times)$, 1,2,4,5-tetraclorobenzene $(*)$, and $n$-ocatadecane $(\bigcirc)$

Table 2 Solubilities of $n$-octadecane and pyrene in supercritical $\mathrm{CO}_{2}$ at various puressure and temperature

\begin{tabular}{|c|c|c|c|c|c|c|}
\hline \multirow{4}{*}{$\begin{array}{c}\text { Solute } \\
(\text { Vapor pressure } / \mathrm{Pa}) \\
n \text {-octadecane } \\
\left(3.3 \times 10^{-3}\right)\end{array}$} & \multicolumn{6}{|c|}{ Solubility/mole fraction } \\
\hline & \multicolumn{3}{|c|}{$40^{\circ} \mathrm{C}$} & \multicolumn{3}{|c|}{$87^{\circ} \mathrm{C}$} \\
\hline & $10 \mathrm{MPa}$ & $20 \mathrm{MPa}$ & $30 \mathrm{MPa}$ & $10 \mathrm{MPa}$ & $20 \mathrm{MPa}$ & $30 \mathrm{MPa}$ \\
\hline & $1.6 \times 10^{-3}$ & $8.6 \times 10^{-3}$ & $\mathrm{n} / \mathrm{a}^{\mathrm{a})}$ & $1.0 \times 10^{-3}$ & $2.2 \times 10^{-3}$ & $\mathrm{n} / \mathrm{a}^{\mathrm{a})}$ \\
\hline \multirow{3}{*}{$\begin{array}{c}\text { pyrene } \\
\left(8.86 \times 10^{-4}\right)\end{array}$} & & $40^{\circ} \mathrm{C}$ & & & $60^{\circ} \mathrm{C}$ & \\
\hline & $10.7 \mathrm{MPa}$ & $20.0 \mathrm{MPa}$ & $30.0 \mathrm{MPa}$ & $11.4 \mathrm{MPa}$ & $20.0 \mathrm{MPa}$ & $30.1 \mathrm{MPa}$ \\
\hline & $5.6 \times 10^{-5}$ & $2.2 \times 10^{-4}$ & $3.2 \times 10^{-4}$ & $2.2 \times 10^{-5}$ & $2.6 \times 10^{-4}$ & $4.8 \times 10^{-4}$ \\
\hline
\end{tabular}

a) n/a : not applicable

的な傾向は，温度一定の条件では圧力とともに溶解度が増 大し, $30 \mathrm{MPa}$ 以上の高圧力側では圧力に対してほぼ一定 となる。また，蒸気圧の高い物質ほど溶解度も高い。一 方, 抽出温度を高くすると, 溶解度の圧力依存性も変化す る、物質に依存したある圧力を境に低圧側では低温のほう が, 高圧力側では高温のほうが溶解度が高くなるという逆 転現象が見られる ${ }^{9)}$. 逆転現象は蒸気圧の低い物質ほど低 圧力側で起こる。溶解度の実測值は一部の物質についてし か求められていないため, $n$-オクタデカンとピレンの溶解 度について本実験条件に近いものを Table 2 によめ た $^{9) 10)}$ ・n-オクタデカンはピレンよりも蒸気圧が高く, 溶 解度も 1 けたから 2 けた高い。また, 同じ圧力では温度 が低いほうが溶解度が高い。一方, ピレンは $20 \mathrm{MPa}$ 及び $30 \mathrm{MPa}$ では温度が高いほうが溶解度が高くなっている.

Fig. 2 の実験結果では, $50^{\circ} \mathrm{C}$ では $n$-オクタデカンの回 収率は抽出圧力に依存しなかったが, 溶解度は圧力上昇に 伴って増大したと推測されることから, 溶解度が回収率の

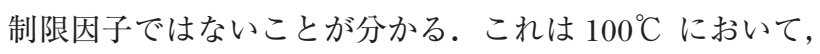
$n$-オクタデカンの溶解度が低下しているにもかからず回収 率は $50^{\circ} \mathrm{C}$ の場合と同等であることからも支持される.テ
トラクロロベンゼンは $n$-オクタデカン同様に蒸気圧の高 い物質である。溶解度データが得られていないため, 詳細 な議論はできないが，少なくとも $50^{\circ} \mathrm{C}$ では $n$-オク夕デカ ンと同じく圧力依存性が小さいため, 溶解度律速の抽出で はないと考えられる.

一方, PAH 類は温度, 圧力共に高いほうが回収率が高 くなる傾向が見られた。溶解度も定性的には $n$-アルカン と同じく増大するものの, 溶解度の増大率ほど回収率が増 大していないことから，PAH 類の抽出においては溶解度 が回収率にかかわる一因子ではあるが，ほかにも因子が存 在することが分かる。

抽出温度は溶解度だけではなく, 吸着物質の脱離・拡散 速度に影響を与える.SFEにおける脱離・拡散速度の定量 的研究はなされてないが, 拡散速度については高温かつ低 圧ほど高いことが分かっている ${ }^{11)}$ 。一方，脱離速度はエネ ルギー的に見れば高温ほど大であり，マトリックスの組成 にも依存すると考えられる。したがって, 圧力一定の場 合, 抽出温度の上昇は脱離・拡散速度を増大させるととも に, 蒸気圧の低いPAH 類においては前述のように溶解度 も高くなるため，回収率は実験結果（Fig. 2）のように高 


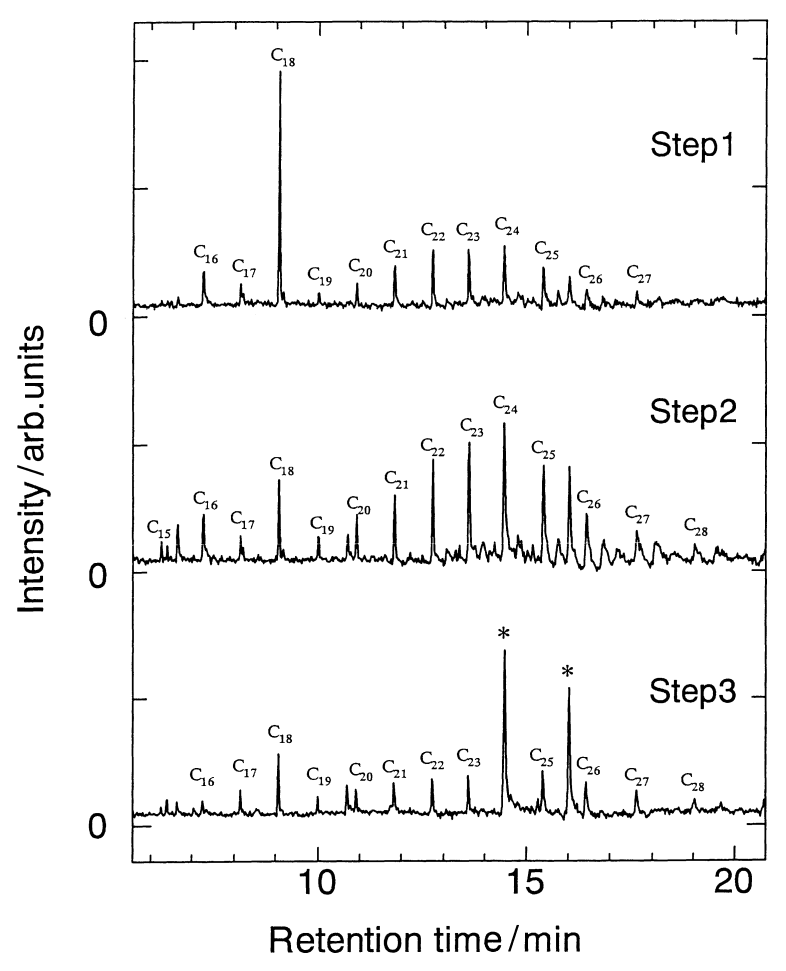

Fig. 3 Selected ion chromatograms $(m / z=57$, fragment peak of $n$-alkanes) at each step of the extraction * denotes peaks other than $n$-alkanes.

温・高圧ほど高くなると考えられる.

\section{$3 \cdot 2$ 実試料における抽出挙動}

モデル試料を用いた実験から，PAH 類の抽出には高 温・高圧条件が適することが分かった。抽出に関与する因 子には溶解度だけではなく, 脱離・拡散過程も含まれるた め, モデル吸着試料と実試料では抽出の振る舞いが異なる ことも予想される。そこで，SPM 粒子に吸着した代表的 な有機化合物について，温度圧力条件を Table 1 に示した 3 段階に変えた段階抽出を行い，各物質の挙動を調べた.

$n$-アルカン類は化石燃料の燃焼と植物起源があり, 炭素 数 $\mathrm{C} 2 \sim \mathrm{C} 36$ のものが合計で大気中に数 $10 \mathrm{ng} / \mathrm{m}^{3}$ 含まれ ている ${ }^{1)}$. 高濃度の $n$-アルカン類は $\mathrm{PAH}$ 類等の有害有機 物を分析する際の典型的きょう雑物となる。 Fig. 3 に $n$ アルカン類の指標となる $m / z=57$ のマスクロマトグラム を示す. Step1 ではC18（n-オクタデカン）の強いピーク とやや弱い C16, C17, C19〜27のピークが検出された. Step2 では $\mathrm{CO}_{2}$ の密度が 2 倍となり, 溶解度が上昇した ため C15〜C28 までの $n$-アルカン類が効果的に抽出され た。前節における $10 \mathrm{ppm}$ のモデル試料では密度の増加は 回収率の向上につながらなかった。この原因としてモデル 試料と SPM ではマトリックスが異なること, 及び SPM で は $n$-アルカンが $10^{3} \mathrm{ppm}$ 程度の高濃度で吸着しているた

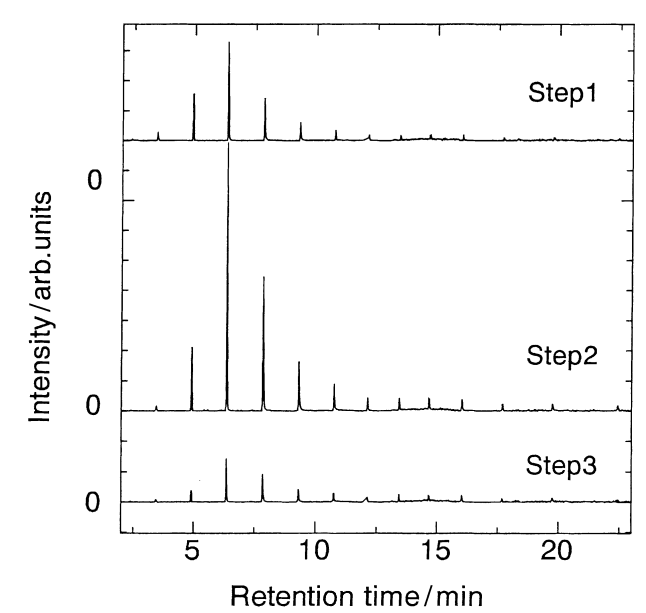

Fig. 4 Selected ion chromatograms $(m / z=73$, fragment peak of polysiloxanes) at each steps of the extraction

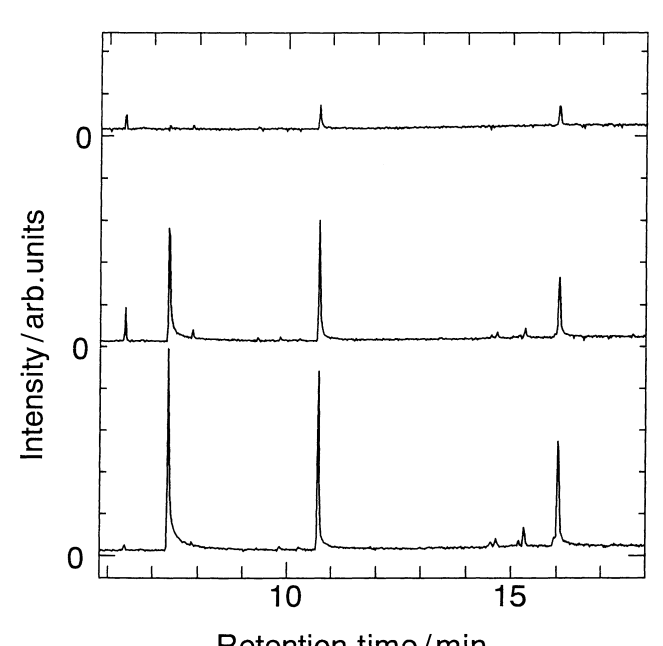

Fig. 5 Selected ion chromatograms $(m / z=149$, fragment peak of phthalates) at each step of the extraction

$め^{12)}$, 密度 (溶解度) が抽出の律速になったものと考えら れる.この傾向は炭素数の大きい $n$-アルカンほど顕著に 見られた. Step3では密度はStep2 と同じであるが，温度 と圧力を更に上昇させた.Step3 ではピーク強度が急激に 減少したため, Step2 までに大部分の $n$-アルカンが抽出さ れたものと考えられる.

$n$-アルカンと同様に繰り返し構造をもつポリシロキサン はエンジンオイルの消泡剤として使用されている. Fig. 4 に示すように，ポリシロキサン $(m / z=73)$ も $n$-アルカ ン同様に Step2 で最も効率的に抽出された.

次にフタル酸エステル類について調べた. Fig. 5 に示す ように，本試料からはフタル酸ジエチル，ジブチル及びジ イソオクチルが検出された。 $n$-アルカン類, ポリシロキサ ン類と異なり, Step1 ではほとんど抽出されず, Step3に 


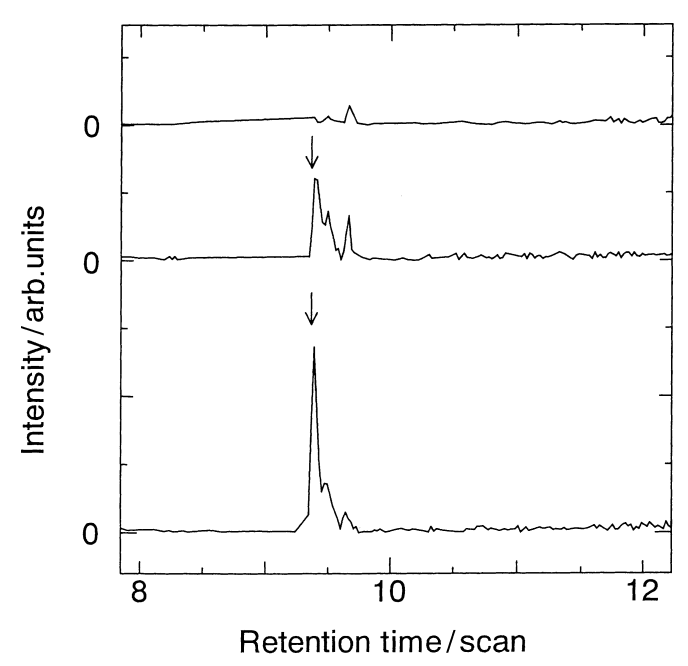

Fig. 6 Selected ion chromatograms $(m / z=178$, parent ion peak of phenanthrene) at each step of the extraction

おいて最も多く抽出された。 また, 3 種のフタル酸エステ ルの分子量と Step ごとのピーク強度に明確な関係はなく, いずれのフタル酸類も Step を追うごとに強度が増大した。

PAH 類のアントラセンは Fig. 2 で示したように，モデ ル試料では高温高圧条件で最大の回収率が得られた。一 方, SPM 実試料の場合は異性体であるフェナントレンが 検出された. Fig. 6 に示すように, フェナントレンもアン トラセン同様 Step1（低温・低圧条件）では全く抽出され ず, Step3で最大のピーク強度となった。

以上の結果から， $n$-アルカンとポリシロキサンといった 直鎖状の物質はStep2 までに大部分が抽出されるのに対 し，フタル酸エステル類や $\mathrm{PAH}$ 類は高温高圧条件で効率 よく抽出されることが分かった．このことは，SFEにおい て温度と圧力を段階的に変化させることにより, 物質群ご との選択回収が可能なことを示唆しており，大量のきょう 雑物に埋もれた微量の分析対象物質を効率よく抽出するた めに有効な手段となり得ると考えられる.

\section{4 結 言}

本研究では, モデル試料を用いて回収率の圧力・温度依 存性を検討し, 実試料における抽出挙動を調査した。得ら れた結果を以下にまとめた。

1）モデル試料において, 回収率の抽出圧力への依存性
は 2 つの傾向に大別され， $n$-オクタデカンとテトラクロロ ベンゼンの回収率は圧力に対して大きな依存性を示さなか ったが, PAH 類（アントラセン, ジクロロアントラセン, ピレン，クリセン）は圧力の上昇に伴って回収率が大幅に 増加する傾向が見られた。

2）抽出温度は溶解度だけではなく, 吸着物質の脱離・ 拡散速度に影響を与える。したがって，一定圧力下では温 度が高くなるほど, 脱離・拡散速度は増大し, 蒸気圧の低 いPAH 類においては溶解度も高くなるため, 回収率は高 温・高圧ほど高くなる傾向を示した。

3）実試料に吸着している代表的な有機化合物について は， $n$-アルカンとポリシロキサンといった直鎖状の物質は 比較的低い温度・圧力条件でも大部分が抽出されるのに対 し, フタル酸エステル類や $\mathrm{PAH}$ 類は高温高圧条件で効率 よく抽出されることが分かった。

4）SFEにおいて温度と圧力を段階的に変化させること により，物質群ごとの選択回収が可能なことを示唆してお り，大量のきょう雑物に埋もれた微量の分析対象物質を効 率よく抽出するために有効な手段となり得ると考えられ る.

\section{文献}

1) N. Yassaa, B. Y. Meklati, A. Cecinato, F. Marino: Atmospheric Environment, 35, 1843 (2001).

2) 久保隆, 小野敬路, 浦野紘平: 大気環境学会誌, 37, 131 (2002).

3) S. B. Hawthorne, D. Miller: Anal. Chem., 66, 4005 (1994).

4) K. D. Bartle, A. A. Clifford: J. Chromatogr. A, 642 , 283 (1993).

5) 小田淳子：分析化学 (Bunseki Kagaku), 48, 595 (1999).

6) 阿尻雅文: 粉体工学会誌, 35, 371 (1998).

7) I. Windal, G. Eppe, A. C. Gridelet, E. De Pauw: J. Chromatogr. A, 819, 187 (1998).

8) G. Soave: J. Supercritical Fluids, 19, 19 (2000).

9) G. Anitescu, L. L. Tavlarides: J. Supercritical Fluids, 10, 175 (1997).

10) J. S. Heath, K. Koblis, S. L. Sager, C. Day: Hydrocarbon Contaminated Soils Volume III, eds. E. J. Calabrese and P. T. Kostecki, Lewis Publishers, Chelsea, MI, pp. 267.

11) D. Mackay, W. Y. Shiu: J. Phys. Ref. Data, 10, 1175 (1981).

12) X. Bi, G. Sheng, P. Peng, Z. Zhang, J. Fu: The Science of the Total Environment, 300, 213 (2002). 
要旨

環境污染有機化合物の分析には，有機溶媒抽出等の前処理が必要であるが，長時間を要する上に操作が煩 雑であるため, 迅速な抽出方法の開発が求められている. 超臨界流体抽出法（SFE）はこれに堪える方法と して注目されている. しかし, 超臨界流体の条件, 被抽出物によって抽出特性が大きく変化するため, 実用 化に際しては基本的な抽出特性の解明が前提となる。 そこで, 多環芳香族炭化水素類 (PAHs)，n-アルカン, ハロゲン化ベンゼンを吸着させたモデル試料を用い，抽出圧力・温度に対する抽出回収率の変化を調査し た. $n$-アルカン, 八ロゲン化ベンゼンの回収率は大きな圧力依存性を示さなかったのに対し, PAHs は高温, 高圧であるほど回収率が上昇した．沿道にて捕集した大気浮遊粒子に低温低圧〜高温高圧の条件で段階的に SFE を適用したところ，n-アルカン，フタル酸エステル類，PAHs が検出された．PAHs の抽出挙動は，モ デル試料の場合と同様に高温高圧段階で効率よく抽出された。この結果より, SFEでは温度と圧力を段階的 に変化させることで物質群の分取が可能なことが示唆された. 